Canadian

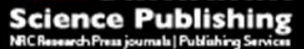

Canadian Journal of Civil Engineering Revue canadienne de génie civil

\title{
Investigating the behaviour of typical and designed wall-to- floor connections in light-frame wood stud wall structures subjected to blast loading
}

\begin{tabular}{|r|l|}
\hline Journal: & Canadian Journal of Civil Engineering \\
\hline Manuscript ID & cjce-2015-0452.R1 \\
\hline Manuscript Type: & Article \\
\hline Date Submitted by the Author: & 08-Feb-2016 \\
\hline Complete List of Authors: & $\begin{array}{l}\text { Viau, Christian; University of Ottawa, Civil Engineering } \\
\text { Doudak, Ghasan; University of Ottawa, Civil Engineering }\end{array}$ \\
\hline Keyword: & $\begin{array}{l}\text { response-blast loading < Struct.Eng. \& Constr.Mate, structure - wood < } \\
\text { Struct.Eng. \& Constr.Mate, light-frame, connections, CSA S850 }\end{array}$ \\
\hline \multicolumn{2}{|l}{} \\
\hline
\end{tabular}

SCHOLARONE ${ }^{m}$

Manuscripts 


\title{
Investigating the behaviour of typical and designed wall-to-floor
}

\section{connections in light-frame wood stud wall structures subjected to}

\section{blast loading}

\section{Christian Viau', Ghasan Doudak ${ }^{2}$}

\begin{abstract}
The performance of light-frame wood stud walls under simulated blast loading has so far been limited to investigating the behaviour of structural elements with idealized boundary conditions. The current study investigates, experimentally and analytically, whether walls with prescriptive connection detailing for low and high seismic and wind regions are capable of resisting blast loadings such that the walls' ultimate capacity can be reached. The study also investigates the behaviour of different connections with various design capacity levels in order to develop failure in the stud wall system rather than in the connection. A total of ten full-scale walls with different boundary conditions were tested dynamically. The results showed that typical prescriptive connection detailing did not perform adequately. Designed connections performed well, but the findings show that basing the connection design solely on capacity may be inadequate. Single degree-of-freedom modelling may only be utilized if damage in the connections is limited.
\end{abstract}

Key words: blast, light-frame, walls, connections, NBCC, capacity, CSA S850, timber, single degree-of-freedom, shock tube.

\footnotetext{
${ }^{1}$ Department of Civil Engineering, University of Ottawa, 161 Louis Pasteur St., Ottawa, ON K1N 6N5, Canada (corresponding author). E-mail: cviau037@uottawa.ca

${ }^{2}$ Department of Civil Engineering, University of Ottawa, 161 Louis Pasteur St., Ottawa, ON K1N 6N5, Canada.
} 


\section{Introduction}

In wood buildings, connections are critical to the building performance as they provide strength, stiffness, stability, and ductility. Few published studies have investigated failures in light-frame wood structures subjected to blast loading, however, experience from post-disaster surveys following earthquake and nuclear events have highlighted deficiencies to properly account for the load paths between structural subsystems such as wall-to-floor and wall-to-foundation connections (Park and van de Lindt 2009; Glasstone and Dolan 1977; Smith 1952). The poor behaviour primarily stems from the fact that such buildings are not designed and detailed by engineers but are rather constructed based on prescriptive requirements. Recent developments in code provisions have significantly enhanced the performance of such structures when subjected to earthquake loading by recognizing the importance of the connections between structural subsystems. For example, recent North American residential codes (NRCC 2015; ICC 2014) now include prescriptive provisions that specifically address design of low-rise light-frame wood structures in high wind and seismic zones.

The performance of light-frame wood stud walls under simulated blast loading has so far been limited to investigating the behaviour of individual studs (Jacques et al. 2014) and full-scale walls with idealized boundary conditions (Viau and Doudak 2015; Lacroix and Doudak 2014; Parlin 2010). The simulation of the boundary conditions as idealized pins may not be realistic but allows for simpler analysis and the ability to isolate the scope of the investigation to the behaviour of the material and components. Some testing on light-frame stud wall structures with actual boundary connections showed apparent deficiencies in typical light-frame wood stud wall structures, however the focus of that study was not on connections (Marchand 2002). These 
studies, albeit limited, have provided crucial information regarding the understanding of the general behaviour of light-frame stud walls.

The intent of the current Canadian blast code (CSA 2012) is to minimize any potential connection failure by overdesigning them, and thereby allowing the load-bearing elements (i.e. studs) to reach their ultimate capacity. The underlying logic is that if failure is to occur in the connections, the system may fail prematurely because the wall would be incapable of reaching its ultimate capacity. This may also cause the wall to become a projectile, thereby injuring or killing occupants of the building. Given that current detailing of light-frame wood structures are prescriptive in nature and with emphasis on gravity loads, it is uncertain whether walls with realistic boundary conditions would be able to develop their full out-of-plane capacity when subjected to a blast pressure.

The current study is part of a larger research program aiming at mitigating damage and injuries associated with blast loading on light-frame wood structures. More specifically, the current study investigates, experimentally and analytically, whether walls with prescriptive connection detailing for low and high seismic and wind regions are capable of resisting blast loading such that the walls' ultimate capacity can be reached. The study also investigates the behaviour of different connections with various design capacity levels in order to develop failure in the stud wall system rather than in the connection. The suitability of current design provisions to ensure proper sequence of failure in the wall is also examined.

\section{Experimental setup and test matrix}

A series of static tests on individual studs, sheathing panels, and connections between sheathing and studs were conducted to establish the capacity and stiffness of all individual wall components prior to the construction and testing of the full-scale stud walls. Obtained data 
include the modulus of rupture and modulus of elasticity of the studs and sheathing panels, as well as the nail-slip relationship for the stud-to-sheathing joint. These data were used to create a material-predictive model which was then validated against the experimental dynamic test results. All tests were conducted according to the designated standards published by the American Society for Testing and Materials (ASTM 2012; 2009; 2006). Sixteen full-scale walls with similar detailing to those reported here, but with idealized boundary conditions, have also been investigated in order to establish a baseline for the wall performance (Viau 2016).

A total of ten full-scale walls with different boundary conditions simulating realistic wall-to-roof or wall-to-floor connections were tested dynamically under shock tube induced blast waves. All walls measured $2070 \mathrm{~mm}$ (81.5 in.) in width, $2108 \mathrm{~mm}$ (83 in.) in height, and the studs had a clear span of $2032 \mathrm{~mm}$ (80 in.), corresponding to the shock tube opening. A detailed summary of the walls' connections can be found in Table 1. Since establishing failure mode and overall performance of the boundary connections was the primary motivation in this study, the top and bottom plates of the test specimens were connected to lumber pieces simulating floor rim joists. The rim joists were attached to the end frame of the shock tube using a hollow steel section (HSS). The blocking simulates typical boundary elements in light-frame wood floor construction and the clamping of the blocking to the shock tube simulates the in-plane stiffness of the floor diaphragm. The dynamic test setup is shown in Figure 1

The tested walls consisted of six 38 × 140 mm ( $2 \times 6$ in.) visually graded No.2 spruce-pine-fir studs spaced at $406 \mathrm{~mm}$ (16 in.) on center with a single top and bottom plate. $11 \mathrm{~mm}(7 / 16 \mathrm{in}$.) thick oriented strand board (OSB) was chosen since this sheathing type and size is predominantly used in light-frame construction in North America. $50 \mathrm{~mm}$ long nails with a diameter of $2.87 \mathrm{~mm}$ were used to fasten the sheathing to the studs using a grid pattern of $150 \mathrm{~mm}$ (field and edge). 
Four commercially available steel connectors were tested as possible options for connecting the wall to its boundary elements. The selection of the connectors was driven by the design capacity of a single stud element based on the respective design standards (CSA 2014; 2012). In order to evaluate whether the design provision is conservative, adequate, or insufficient for blast applications, four connections were detailed to have design capacities which were lower, approximately the same, and higher than that of the stud element.

Simulated blast loads were generated through the use of the University of Ottawa's shock tube. The shock tube is a testing apparatus capable of producing shock waves similar to those found in the far-field detonation of high-explosives. The blocking elements were connected to the top and bottom plates through the use of different connection details, as described in Table 1. The blockings consisted of three $38 \mathrm{~mm}$ x $140 \mathrm{~mm}$ x $2070 \mathrm{~mm}$ lumber pieces connected to each other using $76 \mathrm{~mm} \times 4.2 \mathrm{~mm}$ construction screws. The attachment of the blocking to the specimen is shown in Figure 2a. Figure $2 \mathrm{~b}$ shows the specimen once placed against the shock tube.

The reflected pressure for each test was measured using two dynamic piezoelectric pressure sensors, placed at the shock tube opening. Strain gauges were used on the four middle studs of each wall in order to obtain strain data and determine the dynamic failure point for each test, identifiable by a sudden drop in strain in the strain-time history. The strain rate was calculated by dividing the maximum recorded strain by the time at which maximum strain was recorded. The strain gauges used were general purpose $350 \mathrm{ohms}$ strain gauges, measuring $4.5 \mathrm{~mm} \times 12.5 \mathrm{~mm}$. Mid-span stud deflections for the four middle studs were obtained using $300 \mathrm{~mm}$ stroke linear variable differential transducers (LVDTs). All sensors were connected to a data acquisition system which is capable of recording data at a sampling rate of 100,000 samples per second. A 
high-speed camera was recording the displacement of the wall at 500 frames per second, at a resolution of $800 \times 600$ pixels.

Typical connections requirements defined in Part 9 of the NBCC (NRCC 2015) were used to connect Wall 1, Wall 2, and Wall 3 to the blocking elements. The details of these connections are based on prescriptive requirements for low and high seismic regions, as illustrated in Figure 3. The connections in Wall 4 to Wall 10 were designed based on manufacturer's design specifications based on the design capacity of the wall, which includes a dynamic increase factor (DIF) and a strength increase factor (SIF) as specified in the blast design code (CSA 2012). Their design capacities are summarized in Table 2. The connection detail for Wall 4 and Wall 5 consisted of a standard joist hanger (HU28), typically used in wood floors to connect floor joists to beams or rim joists. Its use here to connect the stud to the top and bottom plates is atypical but seemed appropriate due to the way it wraps around the stud providing a bearing support and a connection to the bottom plate, as shown in Figure 4a. This connector had an expected capacity of $14 \%$ lower than the anticipated dynamic reaction. Walls 6 and 7 were also attached to their respective rim joists using a joist hanger type connector (Figure 4b), however this joist hanger (LJS26DS) had an estimated capacity of approximately $28 \%$ higher than that of the expected dynamic reaction for the tested wall. Walls 8 and 9 were connected using a twist strap typically used to connect stud walls to roof rafters in order to prevent uplift due to wind forces (Figure 4c). This connector was selected because it engages the end of the stud in tension, and could possibly be used as a multi-hazard connector (wind and blast). The expected capacity of this connection is only approximately $2 \%$ higher than the expected dynamic reaction. It should be noted that when using this connector the assumed load path would be different than that of the other three connectors, as the force flows from the studs, through the strap, and directly to the blocking, 
bypassing the top and bottom plates. Wall 10 was connected to its rim joists using an angle plate (Figure 4d) with a design capacity approximately $33 \%$ lower than the expected dynamic reaction. This connector was the easiest and quickest to install, and was also the cheapest. Details on how these connectors were installed are provided in Table 1. Heavy-duty screws were used in these connections based on manufacturer recommendations, and to gain additional withdrawal capacity.

\section{Results and discussions}

A summary of the dynamic testing can be found in Table 3, which presents the reflected pressure and impulse, the duration of the positive phase, and the average of the maximum stud response in terms of displacement and time-to-max displacement. Strain rates between $1.52 \mathrm{E}^{-1}$ to $6.94 \mathrm{E}^{-1} \mathrm{~s}^{-1}$ were generated through the use of the shock tube.

The results from the walls with prescriptive connection detailing (W1, W2, and W3) clearly showed that they were not adequate to withstand the blast pressure prior to the failure of the studs. Such construction detailing are optimized to resist gravity loads or lateral loads in the inplane direction of the wall. In the direction parallel to the wall, the toe nails connecting the rim joists to the wall plates are acting in shear, while in the case of loading in the perpendicular to the wall direction, the toe nails would additionally experience withdrawal. The results also show that even with the enhanced nailing to account for seismic detailing (W2 and W3), the connections, especially at the top plate, were too weak due to the toenails having very low capacity in withdrawal. The tested walls were blown across the laboratory in a rigid body translation, as shown in Figure 5. Failure occurred almost concurrently at the top and bottom plates. Bending in the nails connecting the bottom plate to the blocking was observed, with failure occurring in combination of shear and withdrawal, as shown in Figure 6. The top-plate connection also failed 
by a combination of shear and nail withdrawal failure, as well as nail tearing through the blocking, as they remained attached to the top-plate. The tests on both the non-seismic and the seismic detailing clearly demonstrated the vulnerability of light-frame wood stud walls to the effects of blast loading. It should be noted that light-frame wood structures may have slightly different detailing which could yield better performance. For example, in some cases the sheathing may be constructed so that it extends beyond the top and bottom plates and is attached to the rim joists. This detailing is not common and was therefore not investigated in the current study but it is assumed that this might provide a slightly improved behaviour over the typical connections tested here. The connection performance observed for the prescriptive connections also emphasized the need to design and detail connections in light-frame wood stud walls such that they do not fail before the studs achieving their full capacity.

The results from tests on W4 and W5, where HU28 connectors (see Figure 4a) were used, showed that this connection detail allowed for the studs to reach their ultimate capacity and fail in flexure, as shown in Figure 7. However, a significant number of the screws experienced withdrawal failure, and caused damage to the top and bottom plates (Figure 8). This could be attributed to the fact that the capacity of this connector was $14 \%$ lower than the dynamic reaction. It is, however, noteworthy to mention that providing a connection between the wall and the top and bottom floors, albeit inadequate from a design perspective, still enhanced the performance of the wall significantly compared to the typical prescriptive detailing. The wall studs were capable of achieving their full ultimate flexural capacity with minor debris stemming from the studs and sheathing panels (Figure 7).

The LJS26DS connectors (see Figure 4b) are similar to the HU28 connector but with higher capacity and more fasteners. This connection detail was implemented on W6 and W7, and 
similar to the HU28 connector, the results showed that the studs were able to rotate at their ends, and deflect until reaching failure in flexure. It was evident that using a connector with higher capacity in both shear and withdrawal significantly reduced the damage to the bottom and top plates (Figure 9). Although, the connection design capacity of the LJS26DS connectors was approximately $28 \%$ higher than the dynamic reaction, some damage to the stud ends was still observed. This could possibly be attributed to the high number of fasteners utilized as well as the short end-distance.

W8 and W9 were constructed with the LTS18 connectors (see Figure 4c). Surprisingly, the results in both tests showed similar and poor performance, where the failure was either in rupture of the straps or splitting in the stud, as shown in Figure 10. These failure mode created very hazardous debris, where the studs and sheathing flew across the lab with high velocities. Alternative placement of the straps such that they are effectively wrapping around the stud ends might have produced better results, since splitting would have been reduced. This alternative was not investigated in the study but is suggested for future investigations.

Although the ML24Z connection detail (see Figure 4d) had a design capacity that was $33 \%$ lower than the dynamic reaction, W10 performed reasonably well and all wall studs achieved their ultimate capacity with little damage to the connector (Figure 11a). Damage in the connection was characterized as yielding in the angle and splitting of the studs near the location of the connectors (Figure 11b). This yielding in the connector angle caused a slight increase in rotational stiffness thereby reducing maximum and residual deflections of the stud; the effect of which will be discussed in the modelling section.

The observations from all tested connection configurations indicate that the type of connection (i.e. joist-hangers, angles, straps) and their respective detailing greatly affect the overall 
behaviour of the wall. In other words, basing the design decision for a connection simply on the connection capacity may therefore not be adequate. While not used in typical constructions, connectors that created bearing type support for the studs performed very well and achieved the desired failure mode of ultimately failing the studs in flexure. On the other hand, the strap connector with supposedly adequate design capacity did not perform adequately and caused premature failure and debris. While there was evidence of tension occurring within the straps, splitting failure in the studs may have contributed to this poor performance. An optimization of this connection detail would involve wrapping the LTS18 around the base of the studs, similar to the joist hangers. This would allow the studs to displace without splitting and could potentially transfer a larger portion of the load demand by engaging the connector more in tension.

The findings of the current study clearly show that current design provisions for connections, which are based on the design capacity of the connector alone, are in principle adequate but too simplistic. Connections with performance characteristics that specifically optimize the behaviour of light-frame wood stud walls to blast loading need to be investigated and developed.

\section{Modelling light-frame stud walls with boundary connections}

Previous research has shown that SDOF models can be used to predict the behaviour of various structural elements subjected to blast loading with reasonable accuracy (e.g. Lacroix 2013; Jacques 2011; Lloyd 2010; Syron 2010). These studies, however, dealt mostly with specimens that were tested and modelled using idealized boundary conditions. The test specimens also consistently had a well-defined failure mode, namely flexural failure of the wall studs in the case of light-frame wood stud walls. The introduction of "realistic" boundary conditions would ideally require a model that would permit the inclusion of the effects of rotational restraint due to the boundary connections and the possibility of multiple failure modes in the wall system. The 
current study investigated the appropriateness of using SDOF modeling due to its simplicity and wide use in blast design, and whether simplified assumptions can be made for various connectors. Until verified, one cannot simply assume that a SDOF method can be used for lightframe wood walls with boundary connections, and other more sophisticated modeling techniques may be required.

The SDOF model is based on the equation of deflection for a simply-supported beams, modified for partial composite action between the studs and sheathing. Theoretical deflections were calculated using Equation 1.
$\Delta_{\text {theoretical }}=\frac{W L^{4}}{384 E I_{P C A}}$
Equation 1

Where $\mathrm{W}$ is the uniformly distributed load, $\mathrm{L}$ is the clear span, EI $\mathrm{PCA}_{\mathrm{PA}}$ is the bending stiffness including partial composite action (PCA) effects. The resistance curves used as input into the analytical model were obtained from static testing and modified for high strain-rate effects, partial composite actions, and end restraint (Figure 12). Also included in Figure 12 is the resistance curve of the pin-ended OSB walls studied and reported in a previous study (Viau 2016). It can be observed that all three modelled walls with connection retrofits have the same initial stiffness and ultimate resistance as the simply-supported walls, of $28.53 \mathrm{kN}$. Comparison between walls with boundary connections, reported in this paper, and those previously tested (Viau 2016) with idealized pinned boundary conditions shows that displacement-time histories as well as levels of damage are very similar.

Studs connected with either HU28 or LJS26DS were found to behave as simply-supported, with no evidence of rotational restraint. Whereas the joist hangers (HU28 and LJS26DS) mainly suffered fastener withdrawal, which seems to realistically behave similar to a pin ended 
connection, the non-linearity brought on by the yielding of the ML24Z connector provided a source of energy dissipation, and therefore, a reduction in maximum stud displacement. The scope of the current study only entails developing a simple yet effective methodology by which the effects of end connections are assumed to be negligible. This approach would tend to yield conservative results in the case where the end connections increase stud stiffness, without resorting to resource-heavy finite element model which could potentially capture non-linearity.

Figure 13 shows that the correlation between the experimental and the SDOF model is acceptable for HU28 and LJS26DS connectors, where the failure mode was well defined and the connection's contribution to the rotational stiffness was negligible, therefore behaving as simplysupported boundary connections. Examples of model fits for these connectors are shown in Figures $14 \mathrm{a}$ and $\mathrm{b}$, respectively. The results show that the model tends to slightly under-predict the maximum displacement by an average of $2 \%$. Since rotational restraint effects are ignored when modelling the stiffness of studs equipped with ML24Z end connectors, the model's predicted displacement-time histories will over-estimate maximum stud displacements and timeto-maximum stud displacement by approximately $40 \%$, as shown in Figure 14c. The simplysupported approach for the ML24Z walls lacks the implementation of the non-linear behaviour in the connectors. However, from a blast design point of view, this approach yields conservative results, which is usually the desired approach. The model was unable to accurately predict the displacement-time history of the walls detailed with LTS18 twist straps, as shown in Figure 14d. This is due to the fact that the model assumes flexural failure, which did not occur in W8 and W9.

\section{Design code considerations}


The current design approach in the CSA S850 (2012) standard predicts the performance of structural elements based on their static design strength, modified for dynamic properties through a dynamic increase factor (DIF). The standard has no specific provisions for connections in lightframe wood structural systems but states, in general, that connections between structural elements shall be limited to bearing failure in the wood member or connector and that the connection shall be designed for forces corresponding to 1.2 times the capacity of the components being considered (CSA 2012). This study attempted to verify whether this simplified provision is applicable for a blast scenario by evaluating two variables; the ratio of design capacities between the connections and load-bearing elements, as well as the type of connector used. Considering the ratios between design values shown in Table 2, it can be deduced that while an overdesign factor is in fact appropriate to ensure development of full capacity of the structural elements, the type of connector and construction detailing are of great importance to the performance of the wall system.

It is important to note that the design of connections currently does not include an increase to account for strain-rate effects in the connections. This is assumed to be conservative, however when considering connections in wood structures, the increase due to strain-rate might be dependent on the failure mode and could be significant (e.g. steel strap tension failure vs. wood failure in compression). Furthermore, the strength increase factor (SIF) provided in the code for wood stud walls is assumed to be 1.9, which is found to be conservative for the purpose of designing the studs. On average, this factor is in the range of 2.5 (Lacroix and Doudak 2015; Barrett and Lau 1994). This conservatism is appropriate for purposes of stud design but not for connections design, as the connection design capacity is based on the stud capacity. Although more research is needed in the area of connections used in blast design, it is suggested that a 
higher load be assumed to design the connections than what is currently specified in the blast design code. This would ensure that the studs develop their full capacity, while allowing the designer to use simplified analysis methods such as SDOF models.

The use of SDOF analysis to estimate stud behaviour and wall performance should only be utilized when a predictable failure is expected. The results of this study shows that some connection damage does not seem to significantly affect the predicted displacement. On the other hand, when very heavy damage and failure occurs in the connectors (such as with the LTS18 connections), the wall cannot be modelled by means of simplified analysis such as SDOF modeling.

\section{Conclusions}

This paper highlights the key findings of a study with focus on the behaviour light-frame wood stud walls with boundary connections to floors above and below. The main findings in this study can be summarized as follows:

- Typical nailed connection detailing, even those detailed for high seismic regions, did not possess adequate capacity to maintain connectivity to the floors prior to the wall studs reaching their full capacity. Premature failure of the stud wall assembly was observed and hazardous debris was generated.

- Connector types that had adequate capacity according to the blast design code and that provided bearing support for the wall studs performed well and seemed to have adequate capacity to allow the studs to fail before the connections.

- An angle connector with design capacity less than that required by the code provisions provided adequate performance. Splitting in the studs was observed but this type of 
connector provided partial rotational restraint at the stud end, which reduced the deflection and damage. Due to the non-linear nature of the damage, the use of SDOF modelling, based on the classical linear beam-deflection equation, may not provide accurate results. From a design point of view, using pin-ended conditions as an assumption would yield a conservative prediction of the wall displacement and thereby damage

- From the two previous findings, it can be concluded that basing the connection design solely on the capacity may not be adequate. Additional considerations regarding the connection type and detailing should also be considered.

- Single degree-of-freedom modelling may be utilized if the connections contains limited damage. Walls with excessive yielding or damage to the connection regions require more sophisticated modelling. 


\section{References}

American Society for Testing and Materials (ASTM). 2006. Evaluating Properties of Wood-Base Fiber and Particle Panel Material. ASTM D1037-06a, West Conshohocken, PA.

American Society for Testing and Materials (ASTM). 2009. Static Tests of Lumber in Structural Sizes. ASTM D198-09, West Conshohocken, PA.

American Society for Testing and Materials (ASTM). 2012. Standard Test Methods for Mechanical Fasteners in Wood. ASTM D1761-12, West Conshohocken, PA.

Barrett, J.D., and Lau, W. 1994. Canadian Lumber Properties. Canadian Wood Council, Ottawa, Ontario.

CSA. 2012. Design and assessment of buildings subjected to blast loads. CSA S850-12. Canadian Standards Association, Mississauga, ON.

CSA. 2014. Engineering design in wood. CSA O86-14. Canadian Standards Association, Mississauga, ON.

Glasstone, S., and Dolan, P.J. 1977. The Effects of Nuclear Weapons. Department of Defense, Energy Research and Development Administration, Washington, D.C.

ICC. 2014. International Building Code. International Code Council Inc., Country Club Hills, IL.

Jacques, E., Lloyd, A., Braimah, A., Saatcioglu, M., Doudak, G., and Abdelalim, O. 2014. Influence of high strain-rates on the dynamic flexural material properties of spruce-pine-fir wood studs. Canadian Journal of Civil Engineering, 41: 56-64. doi:10.1139/cjce-2013-0141.

Jacques, E. 2011. Blast Retrofit of Reinforced Concrete Walls and Slabs. MASc thesis, Department of Civil Engineering, University of Ottawa, Ottawa, ON. 
Lacroix, D., and Doudak, G. 2014. Investigation of Dynamic Increase Factors in Light-Frame Wood Stud Walls Subjected to Out-of-Plane Blast Loading. Journal of Structural Engineering, 141(6): 04014159. doi:10.1061/(ASCE)ST.1943-541X.0001139.

Lacroix, D., and Doudak, G. 2015. Experimental and Analytical Evaluation of the Flexural Capacity of Light-Frame Wood Stud Walls Under Blast Loading - An Assessment of the Canadian Blast Design Standard Provisions. Proceedings of the 11th International Conference on Shock \& Impact Loads on Structures, Ottawa, ON., 14-15 May 2015. CI-Premier Conference Organisation, Singapore, pp. 213-221.

Lacroix, D.N. 2013. Behaviour of light-frame wood stud walls subjected to blast loading. MASc thesis, Department of Civil Engineering, University of Ottawa, Ottawa, ON.

Lloyd, A. 2010. Performance of Reinforced Concrete Columns Under Shock Tube Induced Shock Wave Loading. MASc thesis, Department of Civil Engineering, University of Ottawa, Ottawa, ON.

Marchand, K.A. 2002. BAIT, BASS \& RODS Testing Results. USAF Protection Battlelab, The Technical Support Working Group, Defense Threat Reduction Agency, San Antonio, TX.

National Research Council of Canada (NRCC). 2015. National Building Code of Canada, Ottawa, ON.

Park, S., and van de Lindt, J. 2009. Formulation of Seismic Fragilities for a Wood-Frame Building Based on Visually Determined Damage Indexes. Journal of Performance of Constructed Facilities, 23(5): 346-352. doi:10.1061/(ASCE)CF.1943-5509.0000034. 
Parlin, N. J. 2010. Behavior of FRP-Coated Wood Panels under Dynamic Loading. MSc thesis, Department of Civil Engineering, University of Maine, Orono, ME.

Smith, S.B. 1952. Reaction of Buildings to Atomic Blast. The Military Engineer, 44(301): 345353.

Syron, W. 2010. Strain rate-dependent behavior of laminated strand lumber. MSc thesis, Department of Civil Engineering, University of Maine, Orono, ME.

Viau, C. 2016. Investigating the Response of Light-Frame Wood Stud Walls with and Without Boundary Connections to Blast Loads. MASc thesis, Department of Civil Engineering, University of Ottawa, Ottawa, ON.

Viau, C., and Doudak, G. 2015. Behaviour and Retrofit Options for Light-Frame Wood Stud Walls Subjected to Blast Loads. Proceedings of the 11th International Conference on Shock \& Impact Loads on Structures, Ottawa, ON., 14-15 May 2015. CI-Premier Conference Organisation, Singapore, pp. 363-371. 
Table 1 : Summary of dynamic test specimens

\begin{tabular}{|c|c|c|c|c|}
\hline \multirow[b]{2}{*}{$\begin{array}{l}\text { Wall } \\
\text { ID }\end{array}$} & \multirow[b]{2}{*}{ Connection } & \multicolumn{3}{|c|}{ Fastening details } \\
\hline & & $\begin{array}{l}\text { Connector-to- } \\
\text { stud }\end{array}$ & $\begin{array}{l}\text { Connector-to- } \\
\text { plate/blocking }\end{array}$ & Plate-to-blocking \\
\hline W1 & $\begin{array}{c}\text { Nails } \\
\text { (non-seismic) }\end{array}$ & $\mathrm{N} / \mathrm{A}$ & $\mathrm{N} / \mathrm{A}$ & $\begin{array}{c}82 \mathrm{~mm} \text { long nails spaced } \\
\text { at } 400 \mathrm{~mm} \mathrm{o} / \mathrm{c}\end{array}$ \\
\hline $\begin{array}{l}\text { W2 } \\
\text { W3 }\end{array}$ & $\begin{array}{l}\text { Nails } \\
\text { (seismic) }\end{array}$ & $\mathrm{N} / \mathrm{A}$ & $\mathrm{N} / \mathrm{A}$ & $\begin{array}{c}82 \mathrm{~mm} \text { long nails spaced } \\
\text { at } 150 \mathrm{~mm} \mathrm{o} / \mathrm{c}\end{array}$ \\
\hline $\begin{array}{l}\text { W4 } \\
\text { W5 }\end{array}$ & $\begin{array}{l}\text { HU28 joist } \\
\text { hangers }\end{array}$ & $\begin{array}{l}\text { Four } 1-1 / 2 \text { in. } \# 10 \\
\text { screws }\end{array}$ & $\begin{array}{c}\text { Eight } 2-1 / 2 \text { in. \#10 } \\
\text { screws }\end{array}$ & $\begin{array}{c}4-5 / 8 \text { in. }(0.22 \text { in. } \\
\text { diameter) screws installed } \\
\text { in groups of two spaced at } \\
406 \mathrm{~mm}\end{array}$ \\
\hline $\begin{array}{l}\text { W6 } \\
\text { W7 }\end{array}$ & $\begin{array}{l}\text { LJS26DS joist } \\
\text { hangers }\end{array}$ & $\begin{array}{l}\text { Six } 1-1 / 2 \text { in. } \# 10 \\
\text { screws }\end{array}$ & $\begin{array}{l}\text { Sixteen } 2-1 / 2 \text { in. } \\
\quad \# 10 \text { screws }\end{array}$ & $\begin{array}{c}4-5 / 8 \text { in. (0.22 in. } \\
\text { diameter) screws spaced } \\
\text { at } 400 \mathrm{~mm} \mathrm{o} / \mathrm{c}\end{array}$ \\
\hline $\begin{array}{l}\text { W8 } \\
\text { W9 }\end{array}$ & $\begin{array}{c}\text { LTS18 } \\
\text { hurricane twist } \\
\text { straps }\end{array}$ & $\begin{array}{l}\text { Thirteen 1-1/2 in. } \\
\text { \#10 screws }\end{array}$ & $\begin{array}{l}\text { Twelve } 1-1 / 2 \text { in. } \\
\text { \#10 screws }\end{array}$ & $\mathrm{N} / \mathrm{A}$ \\
\hline W10 & $\begin{array}{l}\text { ML24Z steel } \\
\text { angles }\end{array}$ & $\begin{array}{l}\text { Three } 1-1 / 2 \text { in. } \\
\text { (1/4 in. diameter) } \\
\text { heavy-duty screws }\end{array}$ & $\begin{array}{c}\text { Three } 2-1 / 2 \text { in } \\
\text { (1/4 in. diameter) } \\
\text { heavy-duty screws }\end{array}$ & $\begin{array}{c}4-5 / 8 \text { in. ( } 0.22 \text { in. } \\
\text { diameter) screws installed } \\
\text { in groups of two spaced at } \\
400 \mathrm{~mm} \mathrm{o} / \mathrm{c}\end{array}$ \\
\hline
\end{tabular}

Table 2 : Overdesign ratios for retrofitted connections

\begin{tabular}{|c|c|c|c|}
\hline Connection & $\begin{array}{c}\text { Connection design } \\
\text { capacity (kN) }\end{array}$ & Expected failure mode & $\frac{\text { Capacity }_{\text {Connection }}}{\text { Capacity }_{\text {Stud }}}$ \\
\hline HU28 & 10.1 & Shear / withdrawal & 0.86 \\
\hline LJS26DS & 15.1 & Shear / withdrawal & 1.28 \\
\hline ML24Z & 7.9 & Shear / withdrawal & 0.67 \\
\hline LTS18 & 12.0 & Steel rupturing & 1.02 \\
\hline
\end{tabular}


Table 3 : Summary of dynamic test results

\begin{tabular}{|c|c|c|c|c|c|c|c|}
\hline $\begin{array}{c}\text { Test } \\
\text { ID }\end{array}$ & $\begin{array}{c}\text { Wall } \\
\text { mass } \\
(\mathrm{kg})\end{array}$ & $\begin{array}{c}\begin{array}{c}\text { Reflected } \\
\text { pressure }\end{array} \\
\text { (kPa) }\end{array}$ & $\begin{array}{l}\text { Reflected } \\
\text { impulse } \\
\text { (kPa-ms) }\end{array}$ & $\begin{array}{l}\text { Positive } \\
\text { phase } \\
\text { duration } \\
(\mathrm{ms})\end{array}$ & $\begin{array}{l}\text { Average stud } \\
\text { failure } \\
\text { displacement } \\
(\mathrm{mm})\end{array}$ & $\begin{array}{c}\text { Average } \\
\text { time to } \\
\text { max } \\
(\mathrm{ms})\end{array}$ & $\begin{array}{l}\text { Average } \\
\text { strain } \\
\text { rate } \\
\left(\mathrm{s}^{-1}\right)\end{array}$ \\
\hline $\mathrm{W} 1$ & 68.46 & 13.9 & 139.2 & 16.6 & \multirow{3}{*}{$\mathrm{N} / \mathrm{A}^{\dagger}$} & 9.95 & $1.52 \mathrm{E}-1$ \\
\hline $\mathrm{W} 2$ & 68.46 & 41.4 & 302.5 & 16.0 & & 6.98 & $3.20 \mathrm{E}-1$ \\
\hline W3 & 68.66 & 29.3 & 234.6 & 17.4 & & 8.85 & $2.28 \mathrm{E}-1$ \\
\hline W4 & 73.24 & 44.3 & 387.3 & 19.8 & $\mathrm{~N} / \mathrm{A}^{\ddagger}$ & 5.00 & $5.88 \mathrm{E}-1$ \\
\hline W5 & 73.54 & 37.3 & 341.5 & 18.4 & 53.63 & 8.70 & $5.03 \mathrm{E}-1$ \\
\hline W6 & 69.76 & 39.5 & 342.1 & 17.4 & 42.00 & 9.30 & $5.19 \mathrm{E}-1$ \\
\hline W7 & 71.78 & 40.3 & 364.4 & 18.8 & 55.47 & 8.20 & $6.94 \mathrm{E}-1$ \\
\hline W8 & 70.80 & 42.1 & 328.9 & 18.0 & 20.54 & 6.80 & $3.14 \mathrm{E}-1$ \\
\hline W9 & 72.13 & 39.1 & 318.0 & 18.0 & 48.81 & 6.80 & $3.58 \mathrm{E}-1$ \\
\hline W10 & 72.54 & 39.1 & 377.4 & 15.8 & 31.66 & 9.50 & $4.36 \mathrm{E}-1$ \\
\hline
\end{tabular}

${ }^{\dagger}$ Complete wall blowout was expected, therefore LVDTs were not utilized as to not damage them.

${ }^{\ddagger}$ Debris from W4 struck the LVDTs and damaged them, preventing displacement data from being recorded. 


\section{Figure captions}

Fig. 1. Dynamic test setup: (a) side view; and (b) oblique view.

Fig. 2. Simulation of realistic boundary conditions: (a) connecting bottom plate to the blocking (ML24Z detail); and (b) close-up of top plate-to-blocking detail (side view).

Fig. 3. Prescriptive nail connection detail: (a) side view; and (b) front view.

Fig. 4. Tested connections: (a) HU28; (b) LJS26DS; (c) LTS18; and (d) ML24Z.

Fig. 5. Time-lapse of typical connection failure: (a) arrival of shock wave; (b) post-connection failure; and (c) specimen dislodged from test setup.

Fig. 6. Observed bottom plate nail failure mode

Fig. 7. Flexural failure of wall specimen with HU28 connection

Fig. 8. Typical connection damage for HU28 connections

Fig. 9. Damage comparison between HU28 and LJS26DS: (a) LJS26DS connection damage; and (b) HU28 connection damage.

Fig. 10. Observed failure modes for LTS18 walls: (a) splitting failure; and (b) combined rupture/splitting failure.

Fig. 11. Observed effects of ML24Z connection: (a) flexural failure of wall specimen; and (b) yielding of ML24Z.

Fig. 12. Bi-linear resistance curves for various walls

Fig. 13. Comparative view of SDOF and experimental displacements of walls with HU28 and LJS26DS connectors 
Fig. 14. SDOF versus experimental displacement for various walls: (a) W5 (HU28); (b) W7 (LJS26DS); (c) W10 (ML24Z); and (d) W8 (LTS18). 


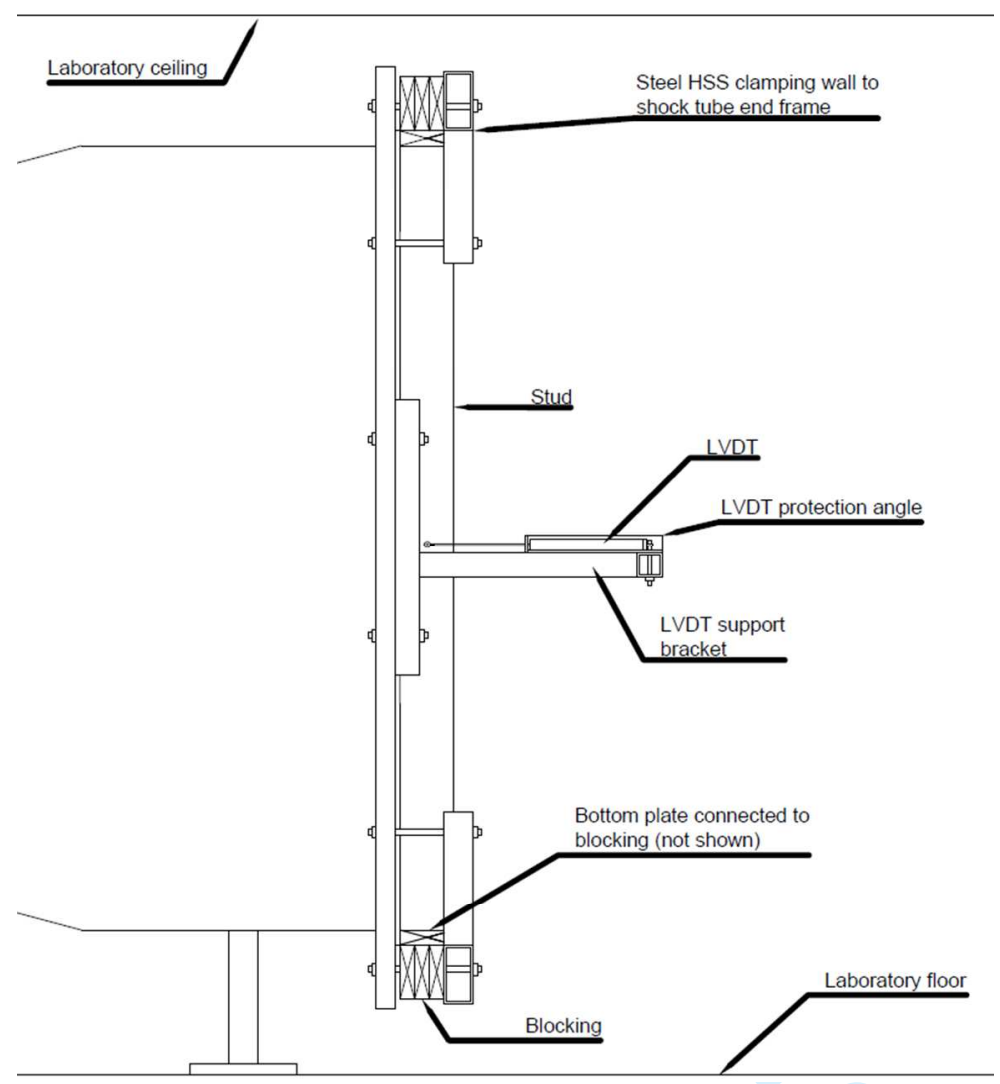

a)

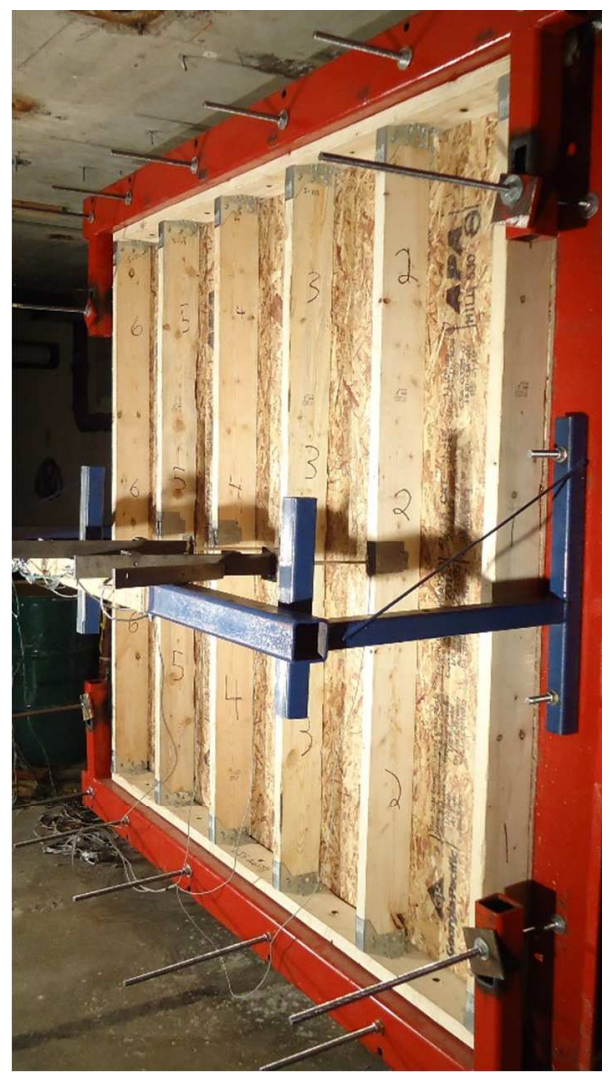

b) 


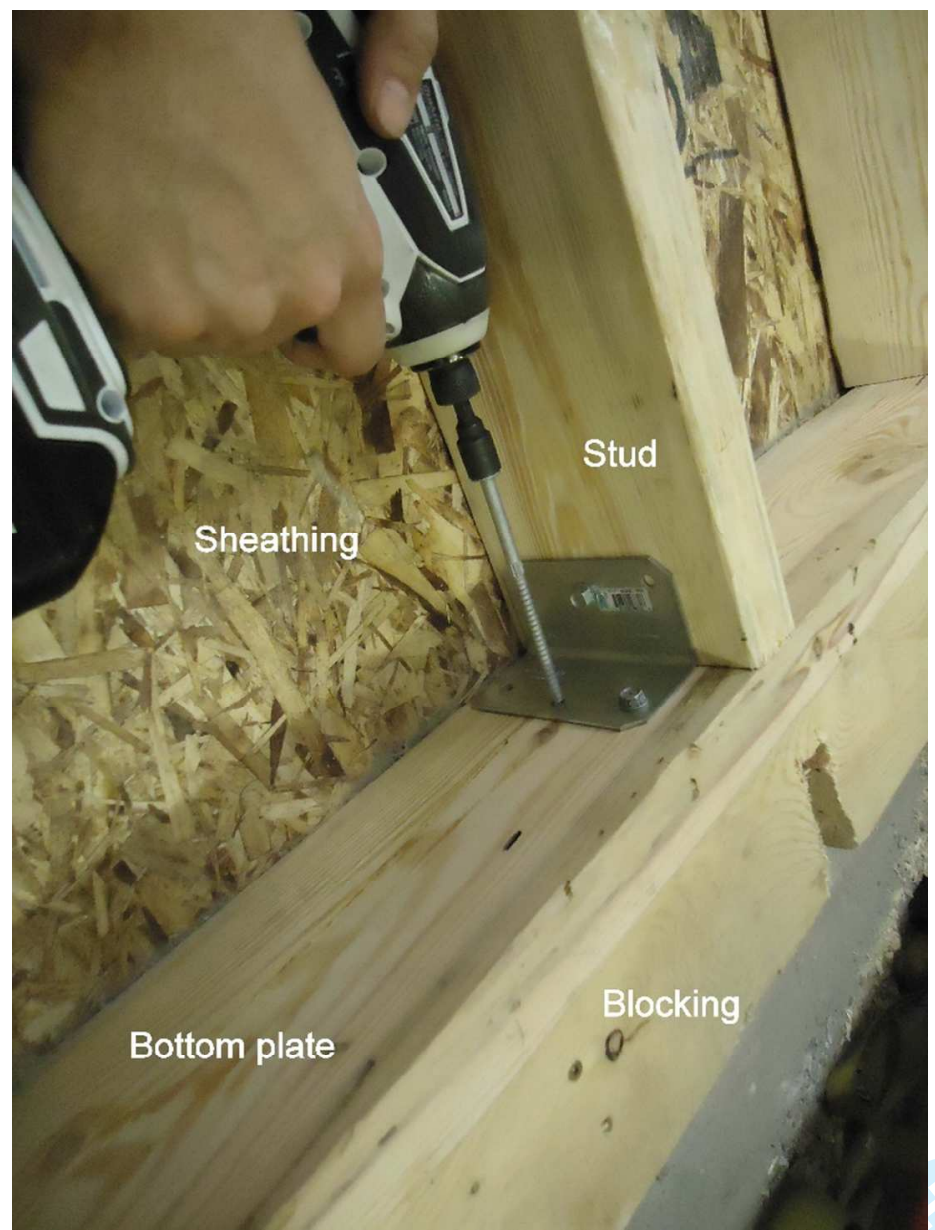

a)

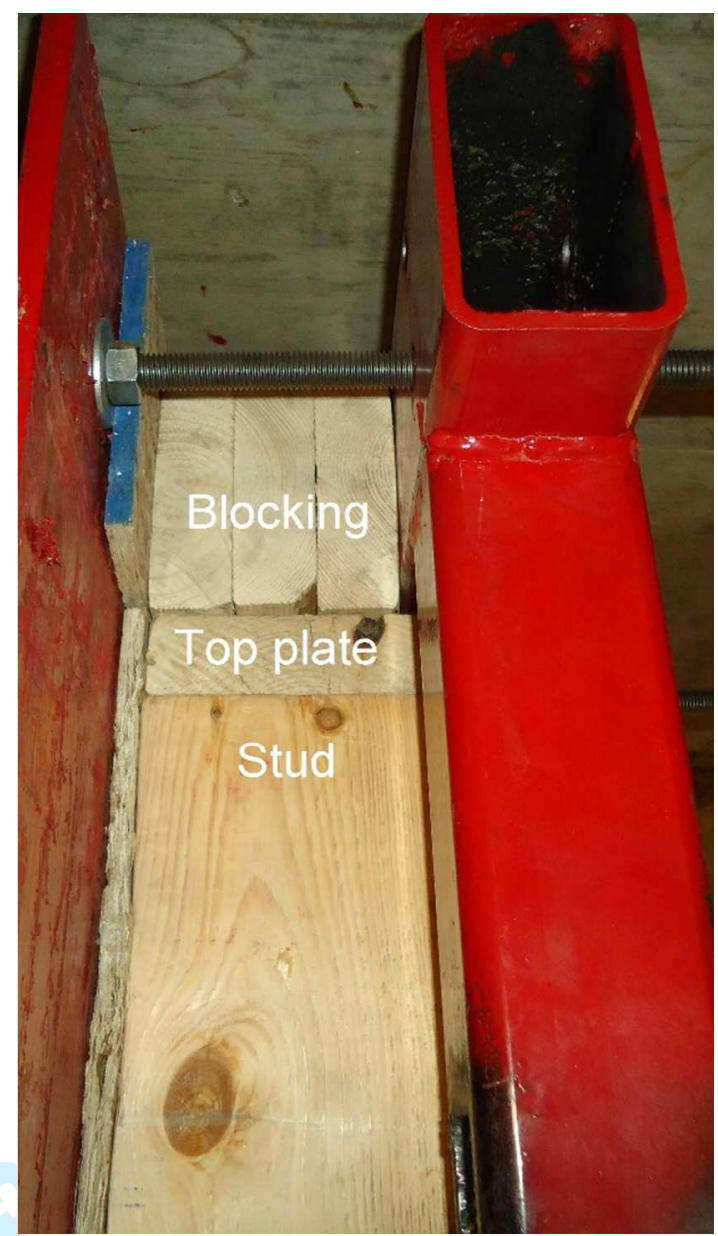

b) 


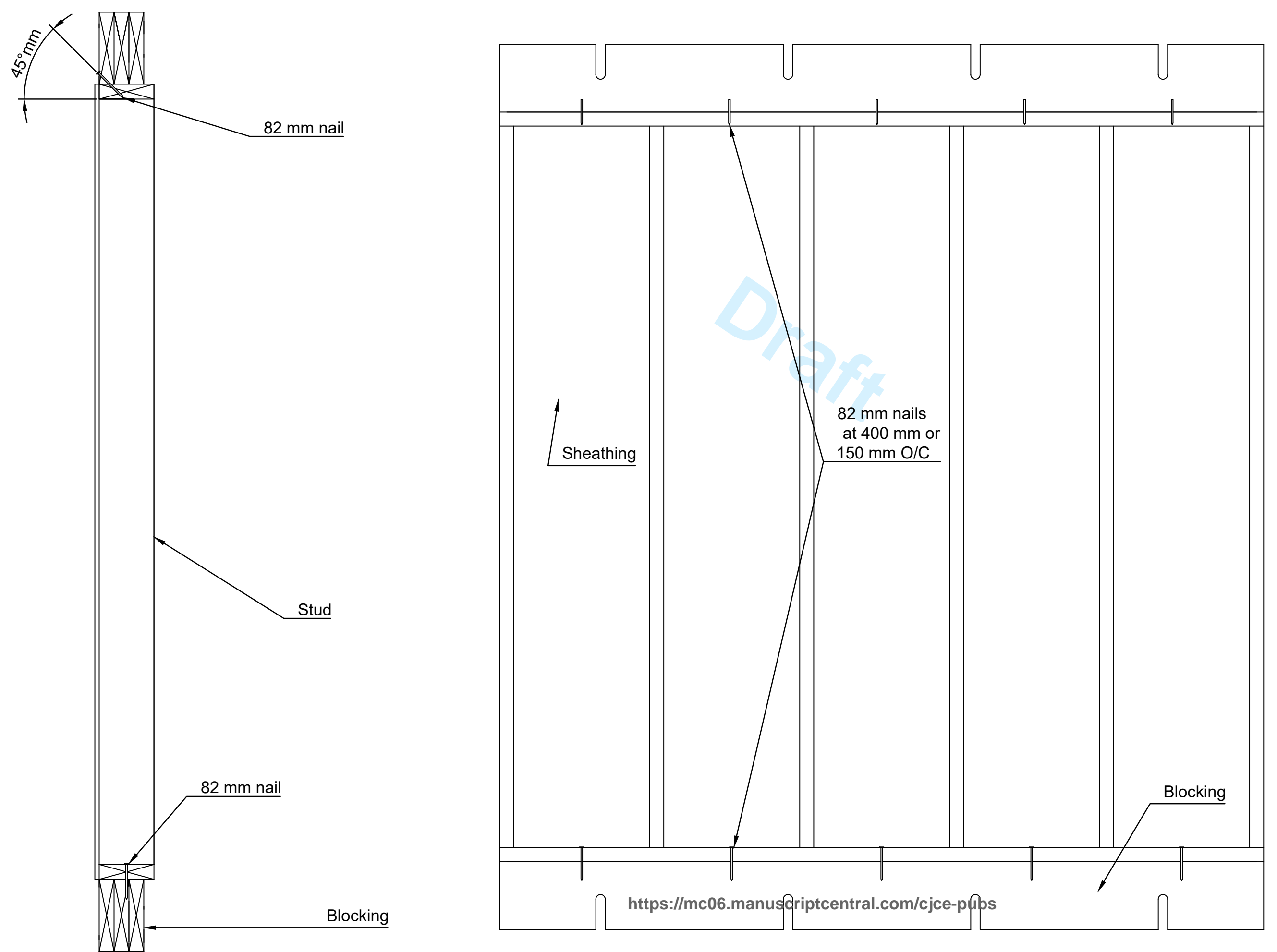




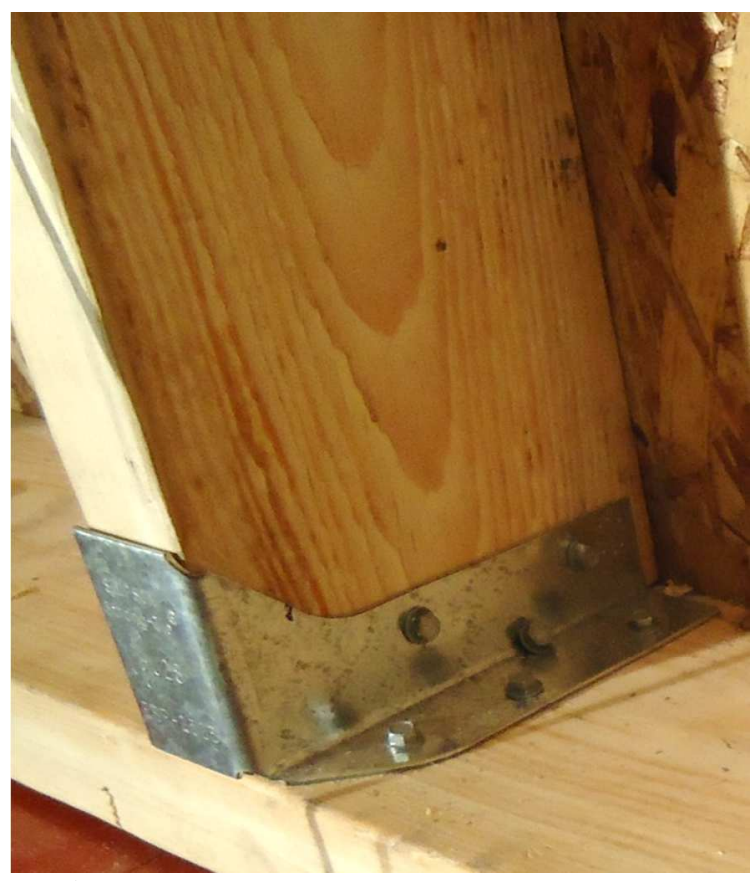

a)

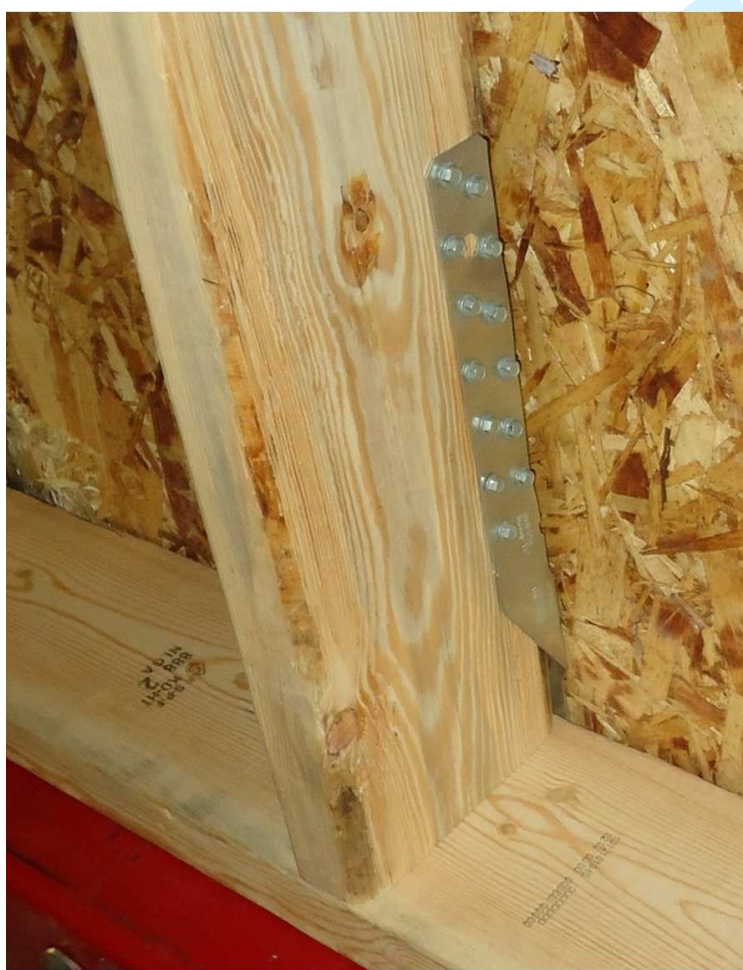

c)

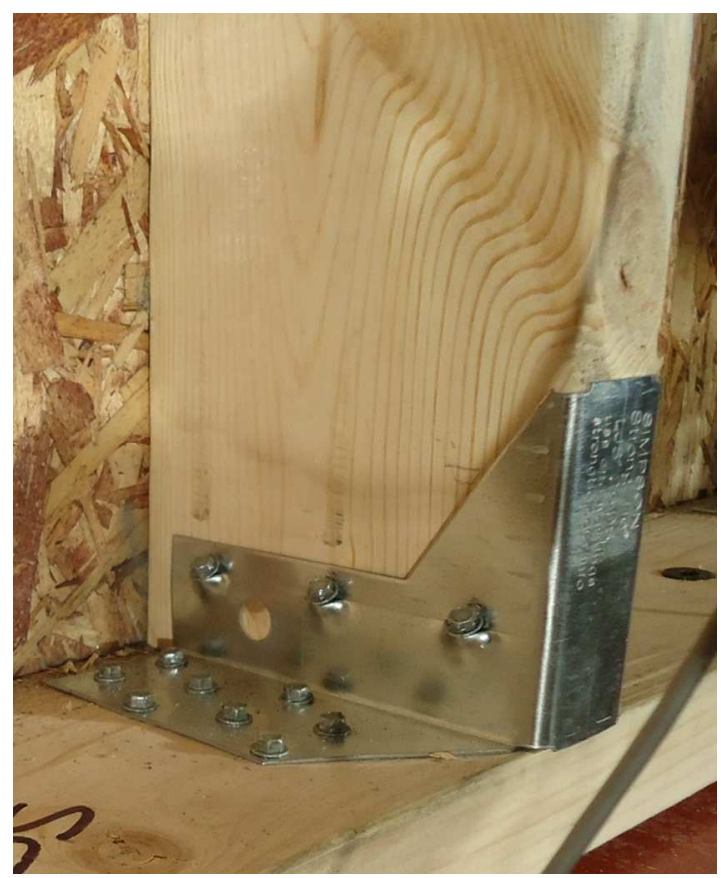

b)

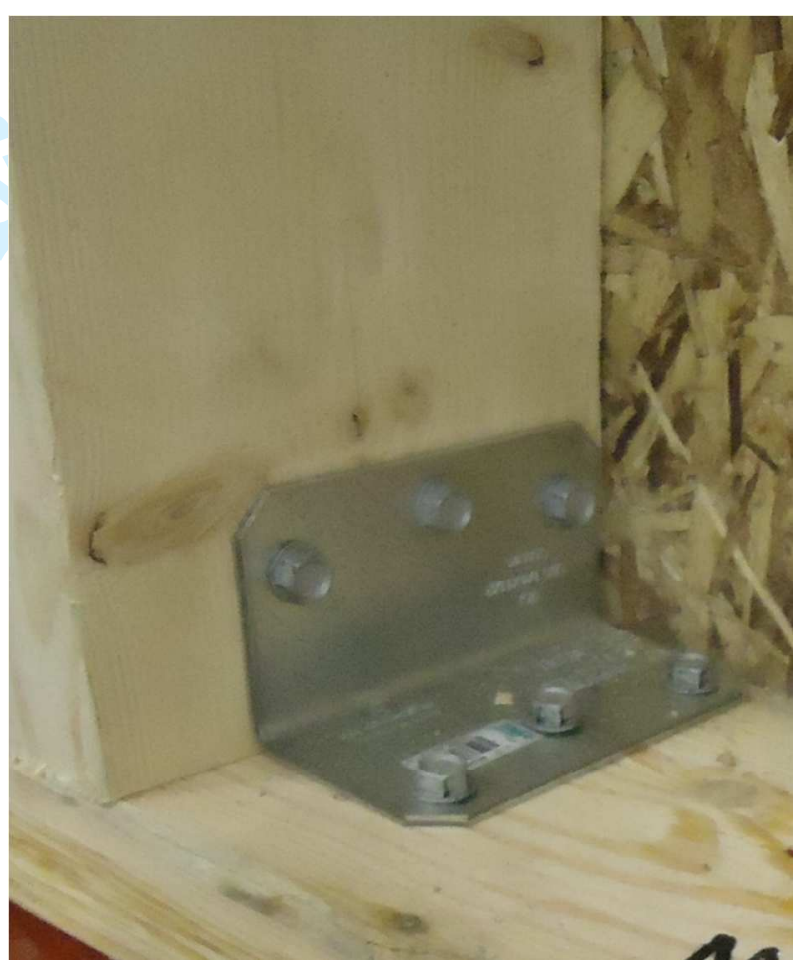

d) 


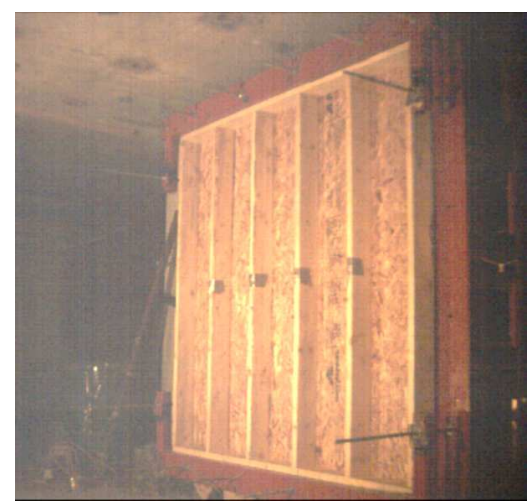

a)

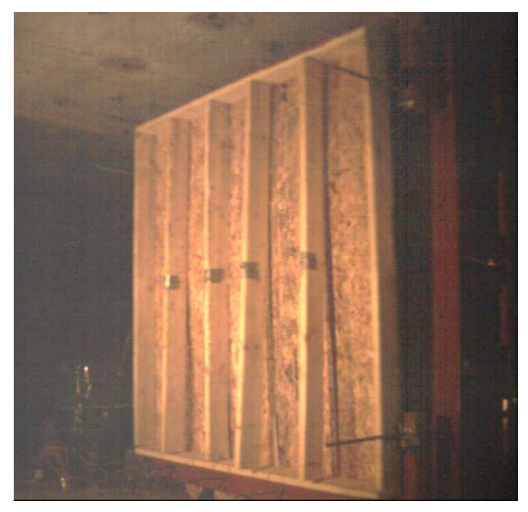

b)

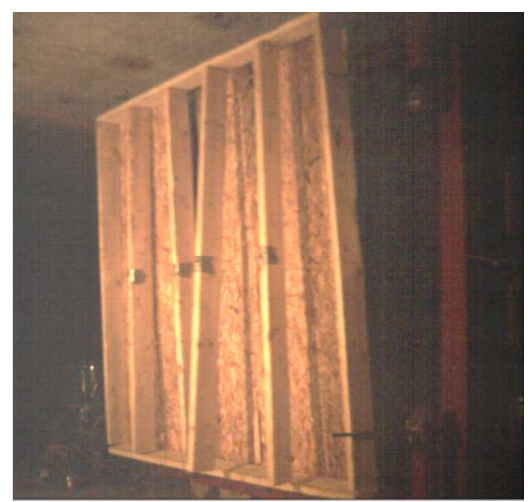

c) 


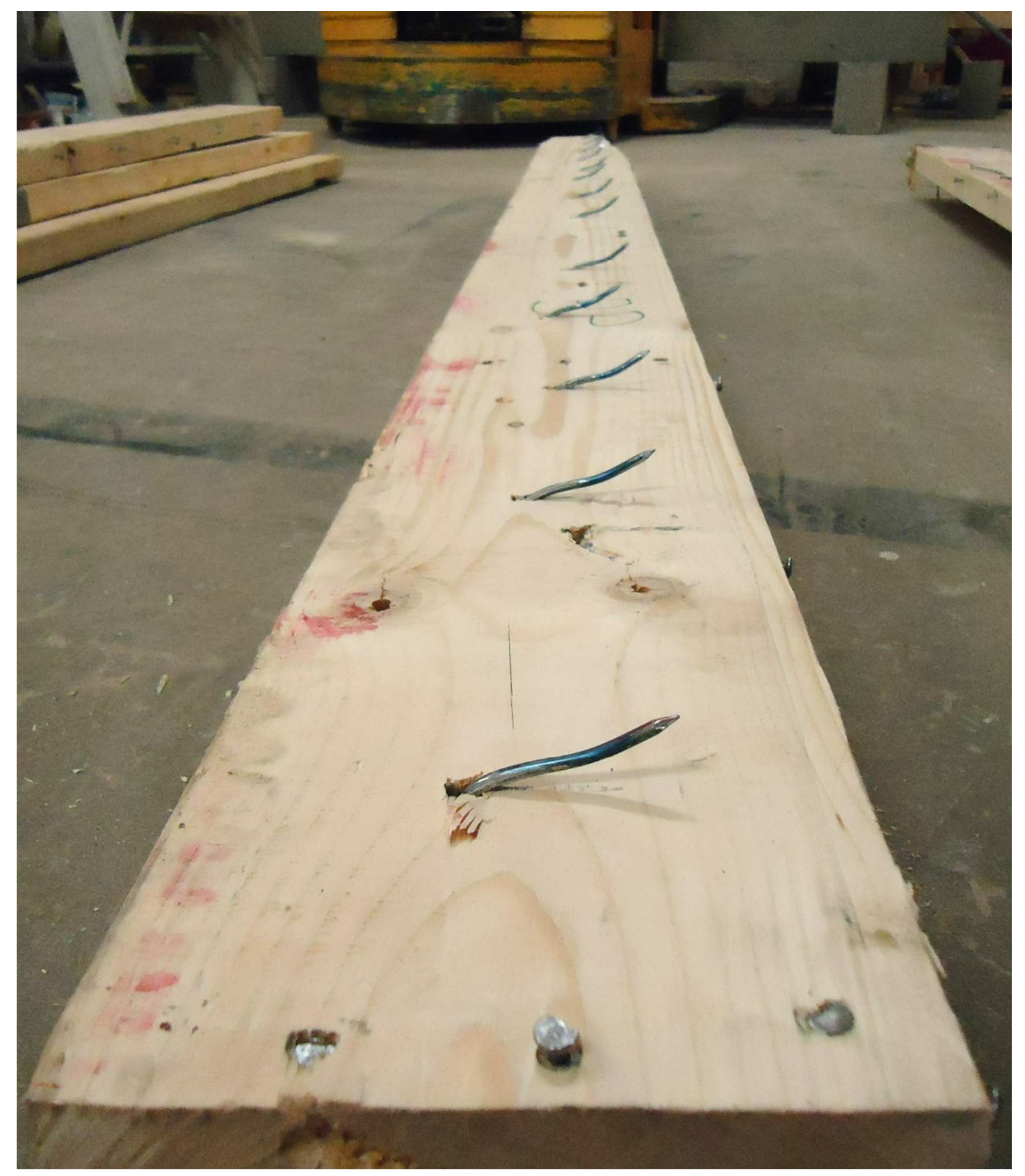




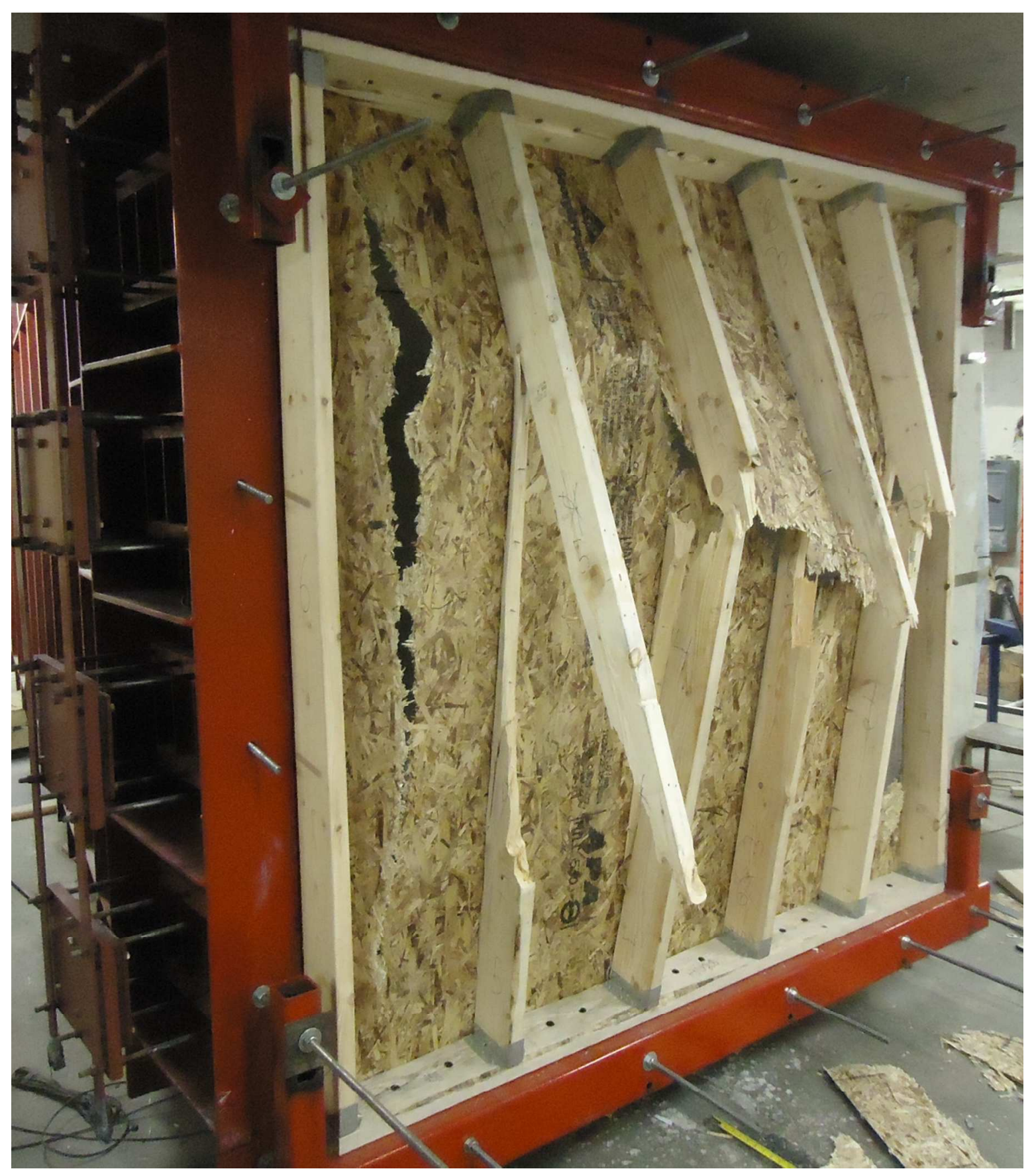




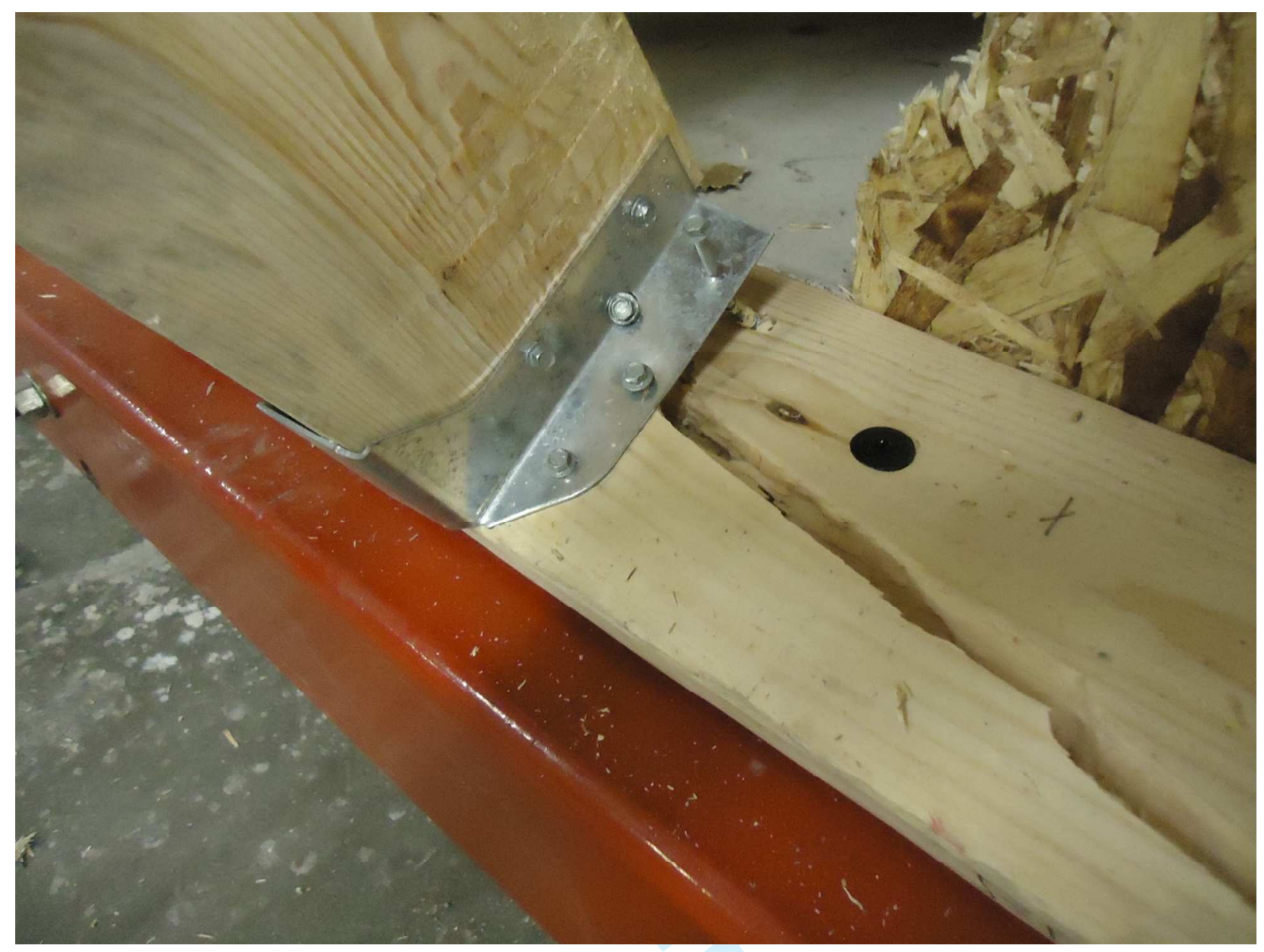



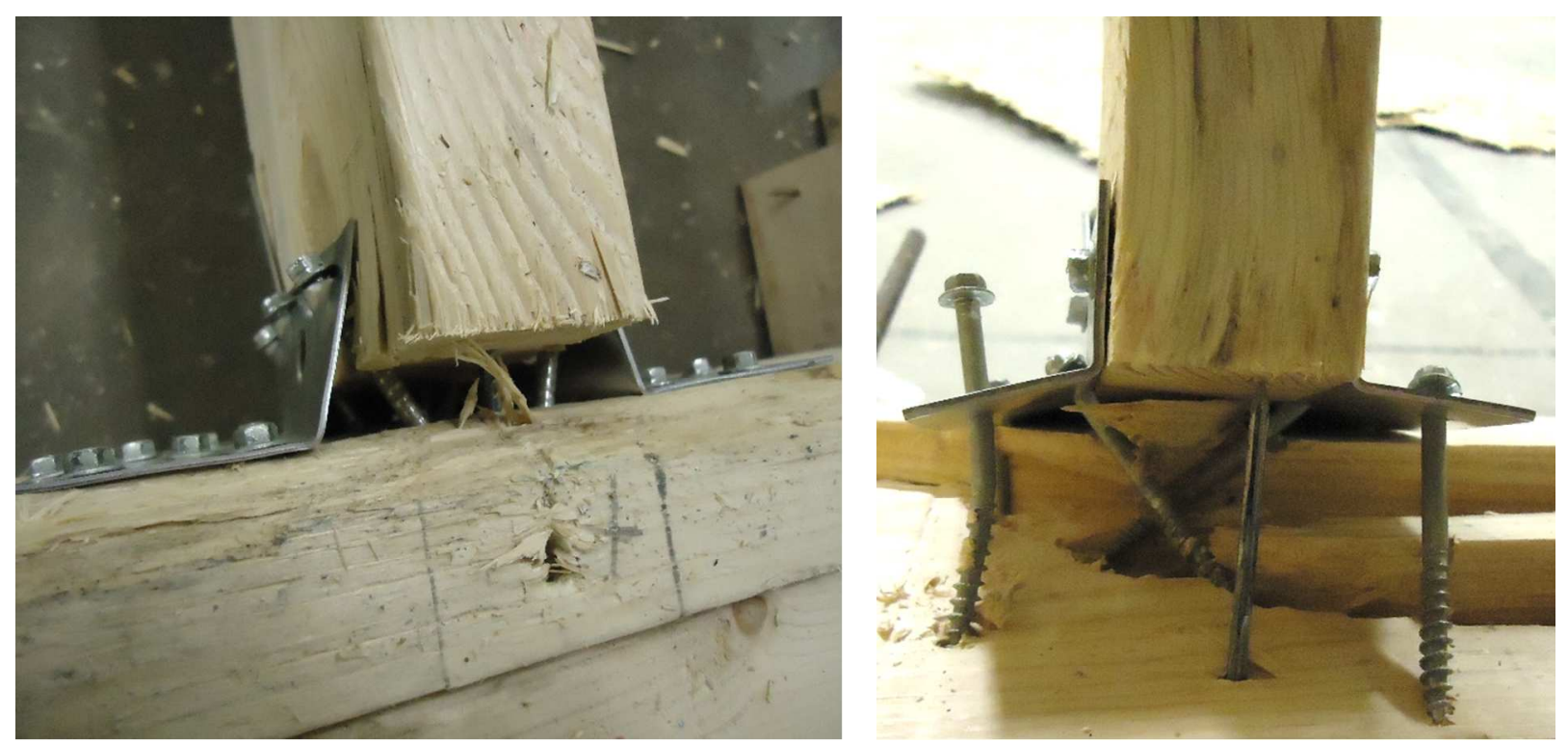

a)

b) 

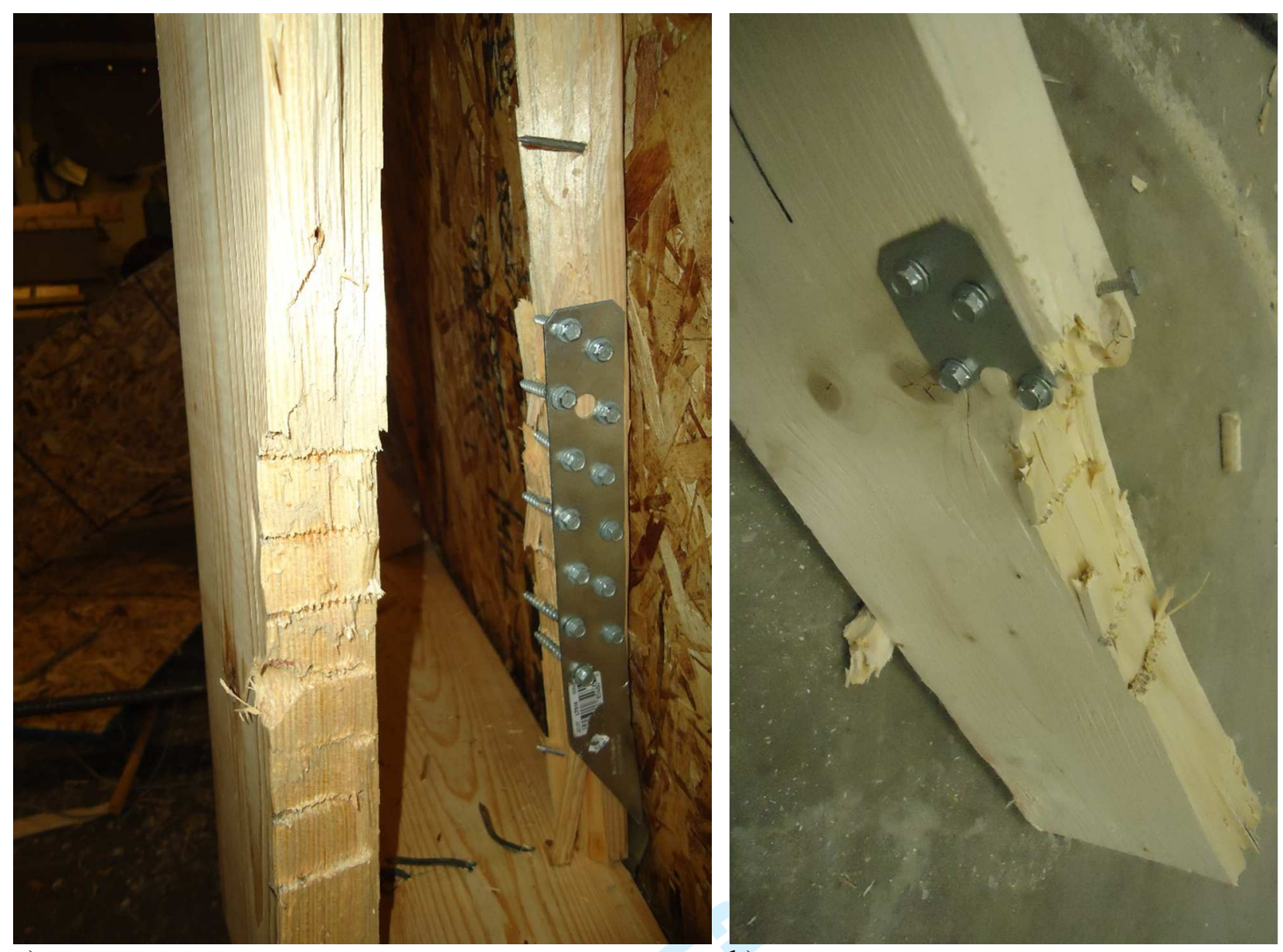

a)

b) 


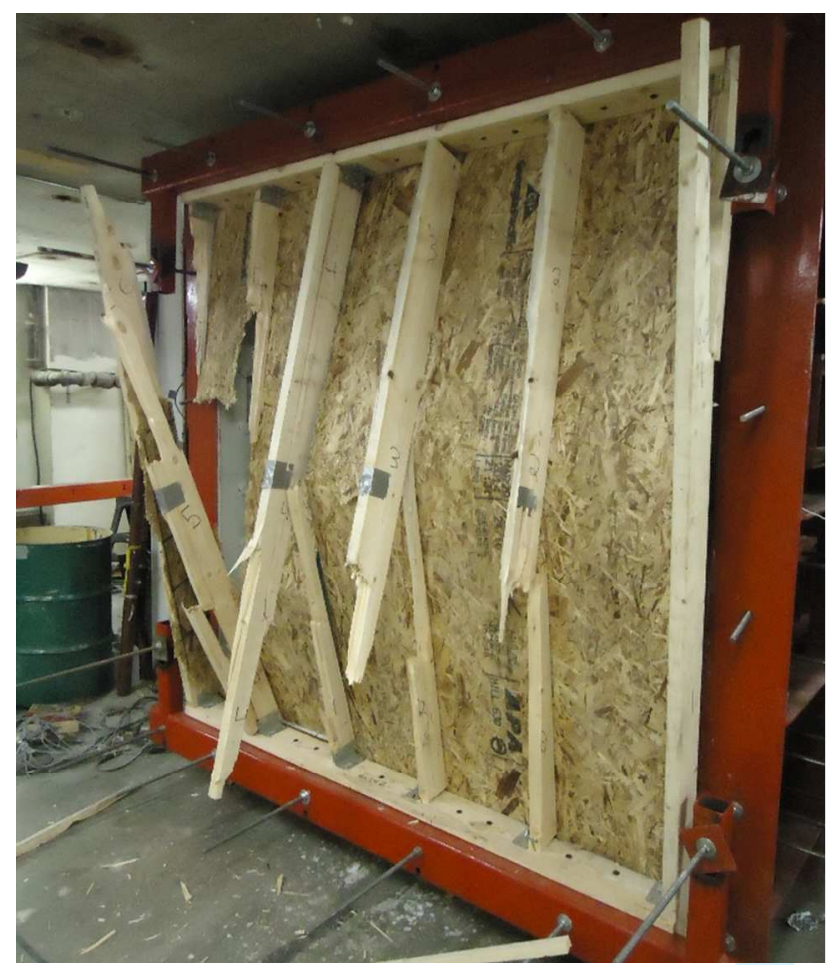

a)

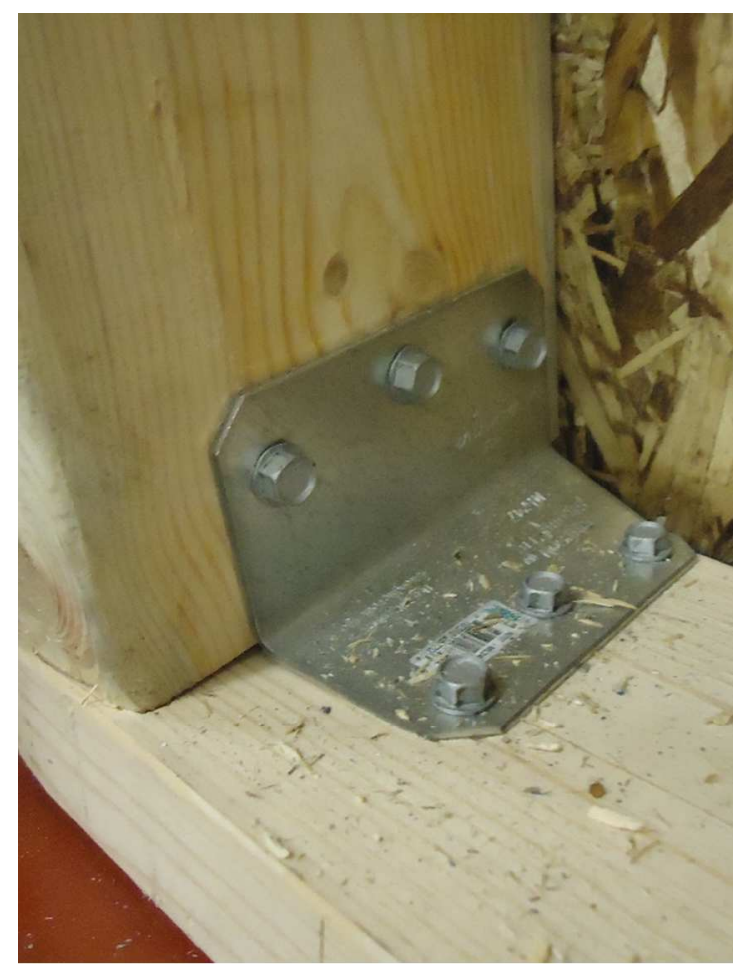

b) 


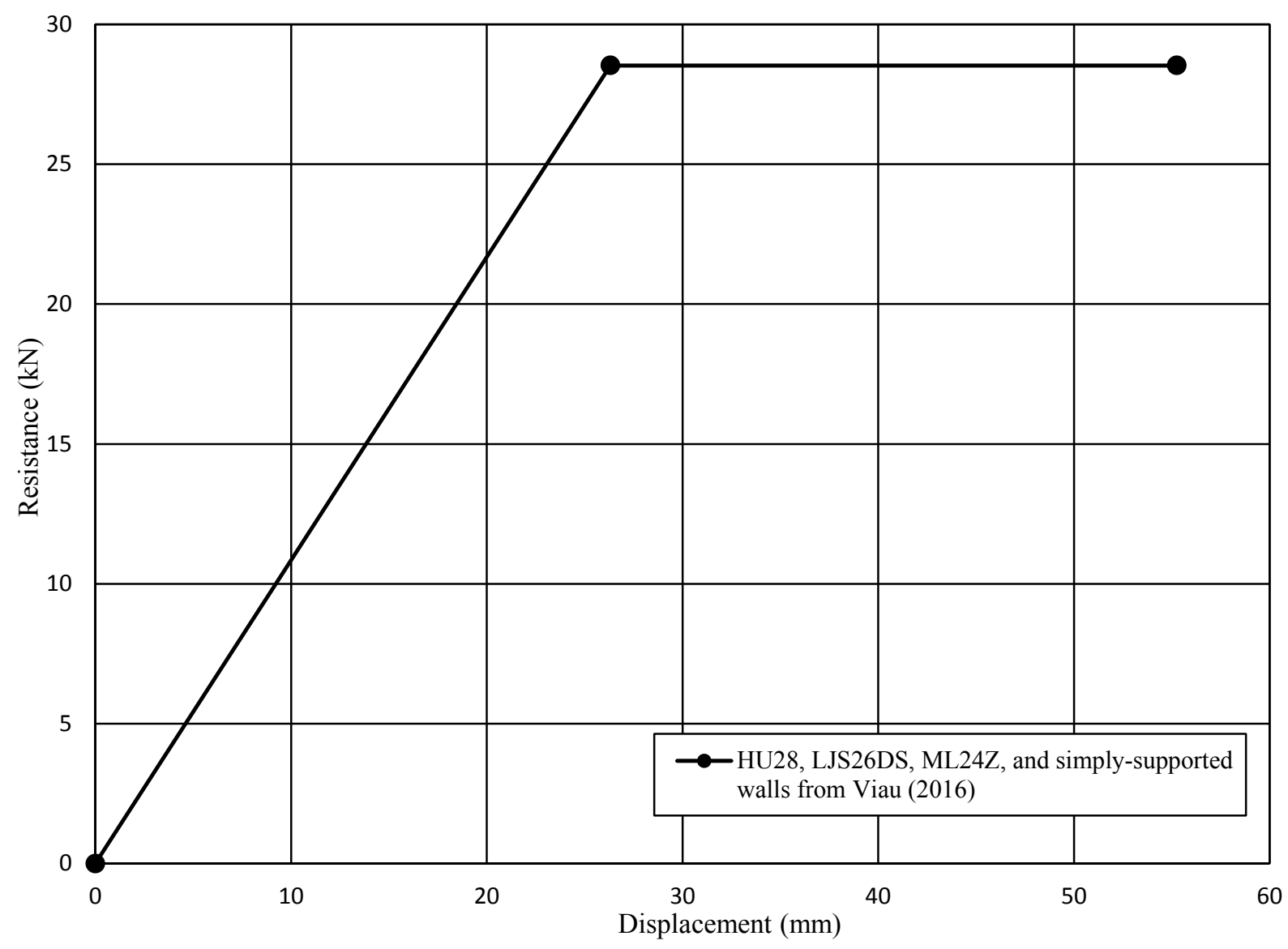




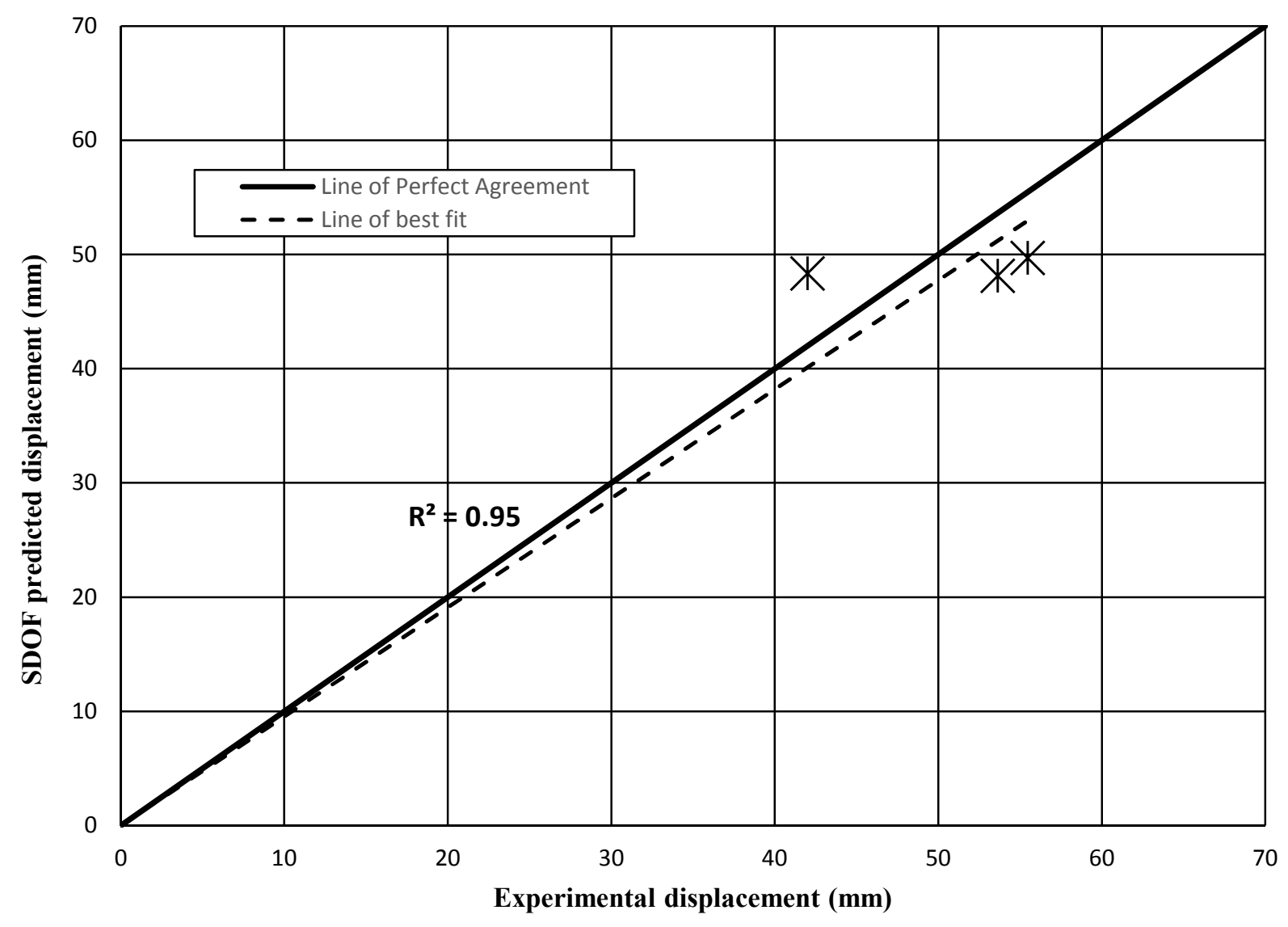




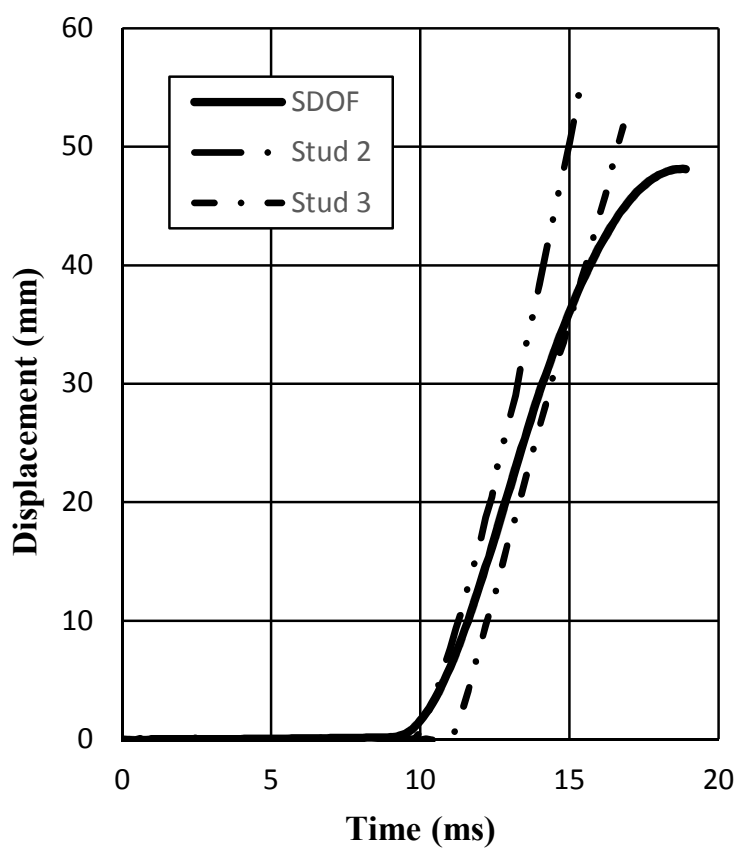

a)

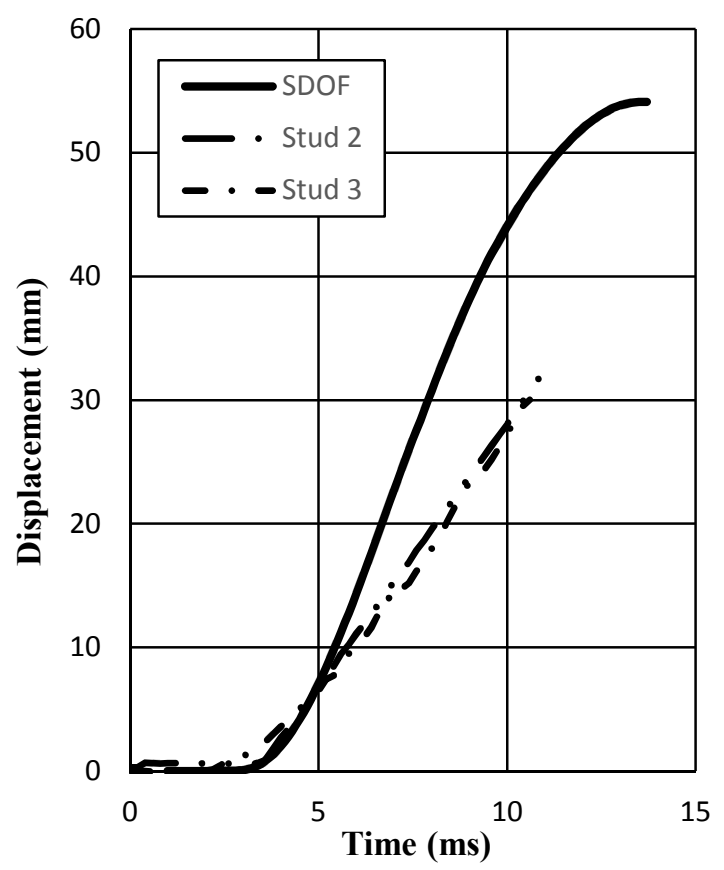

c)

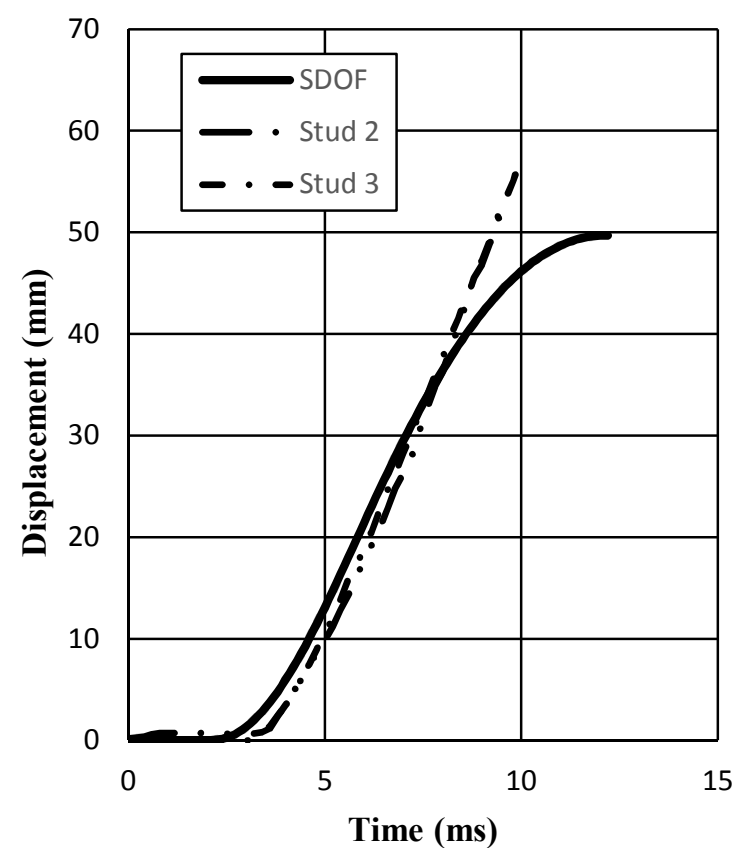

b)

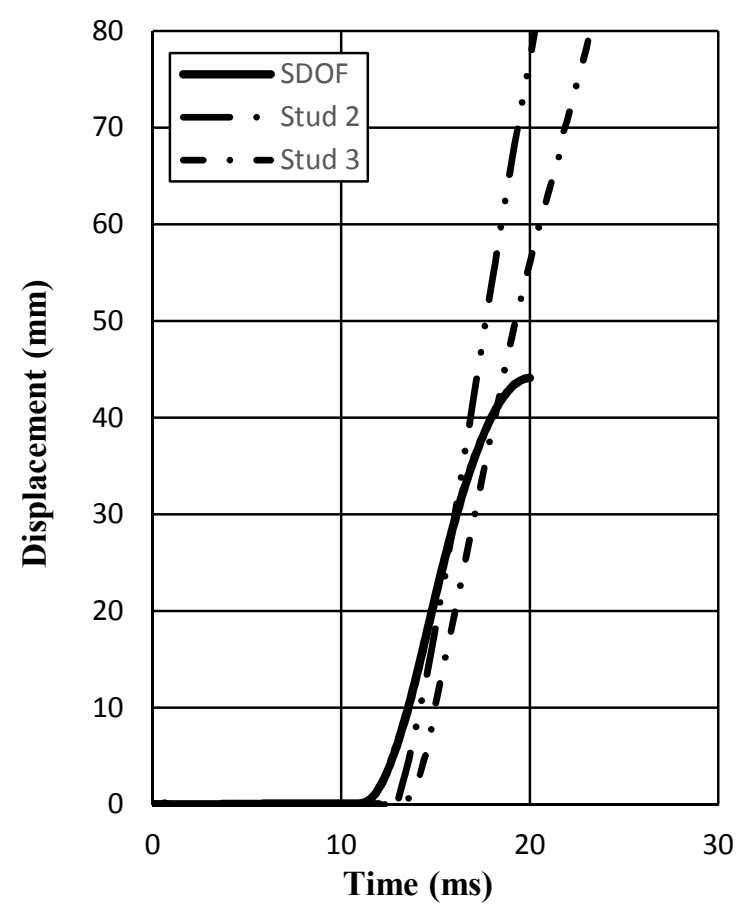

d) 